\title{
Type 2 diabetes mellitus-related changes in left ventricular structure and function in patients with chronic kidney disease
}

\author{
Pei-Yu Wu ${ }^{1,2}$, Jiun-Chi Huang ${ }^{1,2,3}$, Szu-Chia Chen ${ }^{1,2,3}$ and Ling-I Chen ${ }^{1}$ \\ ${ }^{1}$ Division of Nephrology, Department of Internal Medicine, Kaohsiung Medical University Hospital, Kaohsiung Medical \\ University, Kaohsiung, Taiwan \\ ${ }^{2}$ Department of Internal Medicine, Kaohsiung Municipal Hsiao-Kang Hospital, Kaohsiung Medical University, Kaohsiung, \\ Taiwan \\ ${ }^{3}$ Faculty of Medicine, College of Medicine, Kaohsiung Medical University, Kaohsiung, Taiwan
}

Correspondence to: Ling-I Chen, email: 900085kmuh@gmail.com

Keywords: diabetes mellitus; chronic kidney disease; echocardiographic abnormalities

Received: August 08, 2017 Accepted: November 16, 2017 Epub: February 13, 2018 Published: March 06,2018

Copyright: Wu et al. This is an open-access article distributed under the terms of the Creative Commons Attribution License 3.0 (CC BY 3.0), which permits unrestricted use, distribution, and reproduction in any medium, provided the original author and source are credited.

\section{ABSTRACT}

Type 2 Diabetes mellitus (DM) is the leading cause of chronic kidney disease (CKD) worldwide, and is associated with an increased risk of left ventricular (LV) hypertrophy, LV systolic and diastolic dysfunctions. The aim of this study was to investigate abnormal echocardiographic findings in patients with CKD with and without DM, and identify the factors associated with these abnormalities. We enrolled 356 pre-dialysis patients with CKD (stages 3-5), including 208 with DM and 148 without DM. The structure and systolic and diastolic functions of the left ventricle were assessed using echocardiography, and the clinical and echocardiographic parameters were analyzed. The patients with DM had higher rates of observed/ predicted left ventricular mass $>128 \%(69.5 \%$ vs. $56.7 \%, p=0.015)$, midwall fractional shortening < $14 \%(22.6 \%$ vs. $8.8 \%, p=0.001)$, and ratio of peak early transmitral filling wave velocity to early diastolic velocity of lateral mitral annulus $>12(32.7 \%$ vs. $16.2 \%, p<0.001)$ than those without DM. Multivariate analysis showed that male sex, a history of smoking, high systolic blood pressure, high body mass index, high levels of fasting glucose and total cholesterol, low levels of albumin and hemoglobin, and a low estimated glomerular filtration rate were associated with abnormal echocardiographic findings. The rates of inappropriate left ventricular mass, systolic and diastolic dysfunction were higher in our patients with CKD and DM than in those without DM.

\section{INTRODUCTION}

Type 2 diabetes mellitus (DM) is the major cause of chronic kidney disease (CKD) worldwide, and in Taiwanese patients undergoing dialysis it accounts for around $45 \%$ of cases of end-stage renal disease. In addition, type $2 \mathrm{DM}$ has been associated with an increased risk of heart failure (HF), morbidity and mortality $[1,2]$. However, the reason for this increased risk has yet to be fully elucidated, and cannot be fully explained by traditional risk factors for cardiovascular disease (CVD) [2].

Structural and functional abnormalities of the heart have frequently been reported in patients with renal insufficiency due to pressure and volume overload $[3,4]$. In addition, patients with CKD have been associated with high rates of impaired left ventricular (LV) systolic and diastolic function and LV hypertrophy (LVH) [3, 4]. In patients with $\mathrm{DM}$, the most common types of structural and functional heart disease are coronary artery disease (CAD) and diabetic cardiomyopathy, as characterized by LVH, and LV systolic and diastolic dysfunction [5]. Diagnosing preclinical CVD early in this population is important to prevent or delay complications. However, few studies have compared echocardiographic abnormalities in patients with moderate to advanced CKD with and without DM. Therefore, the aims of this study were to compare echocardiographic abnormalities in this population, and evaluate factors associated with these abnormalities in the patients with DM. 


\section{RESULTS}

The mean age of the 356 patients was $66.3 \pm 12.2$ years. Comparisons of the baseline characteristics between the patients with $(n=208)$ and without $(n=148) \mathrm{DM}$ are shown in Table 1. The patients with DM had higher rates of hypertension (HTN), CAD, cerebrovascular disease, proteinuria, anti-hypertensive drug treatment including $\beta$-blockers, calcium channel blockers and diuretics, higher systolic blood pressure (BP) and higher body mass index (BMI) than those without DM. In addition, the patients with DM had higher levels of fasting glucose and triglycerides, and lower levels of hemoglobin and albumin than those without DM. With regards to the echocardiographic parameters, the patients with DM had higher LV endsystolic volume (LVESV), left atrial (LA) diameter, observed/predicted LV mass (LVM) and peak early transmitral filling wave velocity (E)/early diastolic mitral velocity (Ea), and higher rates of $\mathrm{E} / \mathrm{Ea}>12$, observed/ predicted LVM $>128 \%$, midwall fractional shortening $(\mathrm{mwFS})<14 \%$, and LV ejection fraction $(\mathrm{LVEF})<50 \%$, and lower LVEF and mwFS than the patients without DM.

\section{Determinants of inappropriate LVM and increased observed/predicted LVM}

The possible risk factors for an observed/predicted $\mathrm{LVM}>128 \%$ in the patients with DM in multivariate stepwise analysis are shown in Table 2. The results showed that high BMI (per $1 \mathrm{~kg} / \mathrm{m}^{2}$, odds ratio [OR], $1.183 ; 95 \%$ confidence interval $[\mathrm{CI}], 1.071$ to $1.307 ; p$ $=0.001)$ and low estimated glomerular filtration rate (eGFR) (per $1 \mathrm{~mL} / \mathrm{min} / 1.73 \mathrm{~m}^{2}$, OR, 0.961; 95\% CI, 0.936 to $0.987 ; p=0.003$ ) were significantly associated with observed/predicted LVM $>128 \%$ after adjusting for age, sex, a history of smoking, HTN, CAD, cerebrovascular disease, systolic and diastolic BP, BMI, albumin, fasting glucose, triglycerides, total cholesterol, hemoglobin, eGFR, calcium-phosphorous (CaXP) product, uric acid, proteinuria, and the use of medications including ACEIs, ARBs, $\beta$-blockers, calcium channel blockers and diuretics.

Multiple stepwise analysis showed that observed/ predicted LVM was independently correlated with smoking (ever vs. never, unstandardized coefficient $\beta, 16.009$; 95\% CI, 0.761 to $31.257 ; p=0.040$ ), BMI (per $1 \mathrm{~kg} /$ $\mathrm{m}^{2}$, unstandardized coefficient $\beta, 2.089 ; 95 \% \mathrm{CI}, 0.202$ to 3.977; $p=0.030$ ), albumin level (per $1 \mathrm{~g} / \mathrm{dL}$, unstandardized coefficient $\beta,-19.605 ; 95 \%$ CI, -36.773 to $-2.438 ; p=0.025$ ) and eGFR (per $1 \mathrm{~mL} / \mathrm{min} / 1.73 \mathrm{~m}^{2}$, unstandardized coefficient $\beta,-0.586 ; 95 \%$ CI, -1.168 to $-0.004 ; p=0.049$ ) (Table 3).

\section{Determinants of mwFS $<14 \%$ and decreased mwFS}

Multivariate stepwise analysis (Table 2) also revealed that smoking (ever $v s$. never, OR, 2.238; 95\% CI,
1.083 to $4.629 ; p=0.030$ ) and a low albumin level (per 1 $\mathrm{g} / \mathrm{dL}, \mathrm{OR}, 0.399 ; 95 \% \mathrm{CI}, 0.185$ to $0.860 ; p=0.019$ ) were significantly associated with $\mathrm{mwFS}<14 \%$.

Multiple stepwise analysis showed that male sex (versus female sex, unstandardized coefficient $\beta,-1.493$; 95\% CI, 2.641 to $-0.345 ; p=0.011$ ), albumin level (per 1 $\mathrm{g} / \mathrm{dL}$, unstandardized coefficient $\beta, 1.956 ; 95 \% \mathrm{CI}, 0.679$ to $3.234 ; p=0.003$ ), and level of total cholesterol (per $1 \mathrm{mg} / \mathrm{dL}$, unstandardized coefficient $\beta,-0.014 ; 95 \% \mathrm{CI}$, -0.025 to $-0.002 ; p=0.019)$ were significantly correlated with mwFS (Table 3).

\section{Determinants of E/Ea $>12$ and increased E/Ea}

Multivariate stepwise analysis showed significant correlations between high systolic BP (per $1 \mathrm{mmHg}$, OR, $1.017 ; 95 \% \mathrm{CI}, 1.001$ to $1.033 ; p=0.037$ ), high fasting glucose level (per $1 \mathrm{mg} / \mathrm{dL}, \mathrm{OR}, 1.006 ; 95 \% \mathrm{CI}, 1.002$ to $1.011 ; p=0.009$ ) and low hemoglobin level (per $1 \mathrm{~g} / \mathrm{dL}$, OR, $0.640 ; 95 \%$ CI, 0.529 to $0.774 ; p<0.001$ ) and $\mathrm{E} / \mathrm{Ea}>$ 12 in the patients with DM (Table 2).

In addition, multiple stepwise analysis showed that $\mathrm{E} / \mathrm{Ea}$ was independently correlated with systolic $\mathrm{BP}$ (per $1 \mathrm{mmHg}$, unstandardized coefficient $\beta, 0.036$; $95 \% \mathrm{CI}, 0.008$ to $0.063 ; p=0.012$ ), levels of albumin (per $1 \mathrm{~g} / \mathrm{dL}$, unstandardized coefficient $\beta,-1.852 ; 95 \%$ CI, -3.331 to $-0.373 ; p=0.030$ ), fasting glucose (per $1 \mathrm{mg} / \mathrm{dL}$, unstandardized coefficient $\beta, 0.009 ; 95 \%$ CI, 0.000 to $0.017 ; p=0.046$ ), and hemoglobin (per $1 \mathrm{~g} / \mathrm{dL}$, unstandardized coefficient $\beta,-0.728 ; 95 \% \mathrm{CI}$, -1.042 to $-0.413 ; p<0.001$ ), and the use of $\beta$-blockers (unstandardized coefficient $\beta, 1.528 ; 95 \% \mathrm{CI}, 0.247$ to $2.810 ; p=0.020$ ) and diuretics (unstandardized coefficient $\beta, 1.417 ; 95 \%$ CI, 0.102 to $2.732 ; p=0.035$ ) (Table 3).

\section{DISCUSSION}

In this study, we compared echocardiographic abnormalities among patients with CKD stage 3-5 with and without DM, and evaluated the factors associated with these abnormalities in the patients with DM. Our analysis showed that the patients with DM had higher rates of abnormalities including increased LA diameter, inappropriate LVM, and LV systolic and diastolic dysfunction. Furthermore, male sex, smoking, high systolic BP, high BMI, hyperglycemia, a high level of total cholesterol, low levels of hemoglobin and albumin, and low eGFR were associated with abnormal echocardiographic findings in the patients with CKD and DM.

The worse echocardiographic findings including inappropriate LVM, and LV systolic and diastolic dysfunction in the patients with CKD and DM compared to those without DM is an important finding of this study. Hartog et al. suggested the importance of advanced glycation endproducts (AGEs) with regards the pathobiology of HF, in that they may impair both diastolic 
Table 1: Comparison of baseline characteristics between patients with and without DM

\begin{tabular}{|c|c|c|c|c|}
\hline Characteristics & All patients $(n=356)$ & $\begin{array}{l}\text { Without DM } \\
\quad(n=148)\end{array}$ & With DM $(n=208)$ & $p$ \\
\hline Age (year) & $66.3 \pm 12.2$ & $66.4 \pm 12.9$ & $66.2 \pm 11.8$ & 0.914 \\
\hline Male gender $(\%)$ & 62.9 & 66.2 & 60.6 & 0.278 \\
\hline Smoking history (\%) & 31.7 & 32.4 & 31.3 & 0.813 \\
\hline Hypertension (\%) & 83.7 & 78.4 & 87.5 & 0.022 \\
\hline Coronary artery disease $(\%)$ & 11.8 & 7.4 & 14.9 & 0.031 \\
\hline Cerebrovascular disease $(\%)$ & 15.2 & 8.1 & 20.2 & 0.002 \\
\hline Systolic blood pressure (mmHg) & $142.7 \pm 21.8$ & $137.9 \pm 20.1$ & $146.0 \pm 22.4$ & 0.001 \\
\hline Diastolic blood pressure $(\mathrm{mmHg})$ & $79.2 \pm 13.1$ & $80.3 \pm 12.4$ & $78.3 \pm 13.5$ & 0.162 \\
\hline Body mass index $\left(\mathrm{kg} / \mathrm{m}^{2}\right)$ & $25.5 \pm 4.0$ & $24.7 \pm 4.1$ & $26.1 \pm 3.8$ & 0.002 \\
\hline \multicolumn{5}{|l|}{ Laboratory parameters } \\
\hline Albumin (g/dL) & $4.0 \pm 0.4$ & $4.1 \pm 0.3$ & $4.0 \pm 0.4$ & $<0.001$ \\
\hline Fasting glucose $(\mathrm{mg} / \mathrm{dL})$ & $127.7 \pm 60.0$ & $100.3 \pm 16.2$ & $147.7 \pm 71.3$ & $<0.001$ \\
\hline Triglyceride (mg/dL) & $144(97-200)$ & $123(89.5-175)$ & $158.5(105.8-221.5)$ & $<0.001$ \\
\hline Total cholesterol (mg/dL) & $196.4 \pm 46.4$ & $192.9 \pm 43.1$ & $198.9 \pm 48.8$ & 0.228 \\
\hline Hemoglobin (g/dL) & $11.5 \pm 2.3$ & $11.9 \pm 2.3$ & $11.3 \pm 2.2$ & 0.018 \\
\hline eGFR $\left(\mathrm{mL} / \mathrm{min} / 1.73 \mathrm{~m}^{2}\right)$ & $25.7 \pm 14.2$ & $26.6 \pm 15.3$ & $25.0 \pm 13.4$ & 0.308 \\
\hline $\mathrm{CaXP}$ product $\left(\mathrm{mg}^{2} / \mathrm{dL}^{2}\right)$ & $38.6 \pm 9.1$ & $37.8 \pm 8.9$ & $39.1 \pm 9.3$ & 0.196 \\
\hline Uric acid (mg/dL) & $8.1 \pm 2.2$ & $7.9 \pm 2.1$ & $8.3 \pm 2.4$ & 0.095 \\
\hline Proteinuria $(\%)$ & 66.2 & 58.5 & 71.6 & 0.010 \\
\hline \multicolumn{5}{|l|}{ Echocardiographic data } \\
\hline LVEDV (ml) & $118.2 \pm 40.2$ & $114.6 \pm 31.8$ & $120.7 \pm 45.2$ & 0.133 \\
\hline LVESV (ml) & $39.5 \pm 27.0$ & $35.3 \pm 16.5$ & $42.5 \pm 32.2$ & 0.006 \\
\hline $\mathrm{LAD}(\mathrm{cm})$ & $3.8 \pm 0.6$ & $3.6 \pm 0.6$ & $3.9 \pm 0.6$ & $<0.001$ \\
\hline LVMI $\left(\mathrm{g} / \mathrm{m}^{2}\right)$ & $137.1 \pm 47.8$ & $131.4 \pm 45.4$ & $141.1 \pm 49.1$ & 0.060 \\
\hline LVH (\%) & 55.1 & 49.3 & 59.1 & 0.067 \\
\hline Observed/predicted LVM (\%) & $148.3 \pm 47.7$ & $140.7 \pm 41.1$ & $153.6 \pm 51.2$ & 0.011 \\
\hline $\begin{array}{l}\text { Observed/predicted LVM }>128 \% \\
(\%)\end{array}$ & 64.2 & 56.7 & 69.5 & 0.015 \\
\hline LVEF (\%) & $68.1 \pm 10.8$ & $70.0 \pm 8.3$ & $66.7 \pm 12.1$ & 0.003 \\
\hline LVEF < 50\% (\%) & 5.1 & 2.0 & 7.2 & 0.029 \\
\hline mwFS $(\%)$ & $16.9 \pm 3.6$ & $17.6 \pm 2.8$ & $16.3 \pm 4.0$ & $<0.001$ \\
\hline mwFS < 14\% $(\%)$ & 16.9 & 8.8 & 22.6 & 0.001 \\
\hline EDT (ms) & $224.3 \pm 66.1$ & $228.1 \pm 67.4$ & $221.6 \pm 65.2$ & 0.357 \\
\hline $\mathrm{E} / \mathrm{Ea}$ & $10.3 \pm 4.9$ & $9.0 \pm 4.3$ & $11.3 \pm 5.0$ & $<0.001$ \\
\hline $\mathrm{E} / \mathrm{Ea}>12(\%)$ & 25.8 & 16.2 & 32.7 & $<0.001$ \\
\hline \multicolumn{5}{|l|}{ Medications } \\
\hline $\mathrm{ACEI}$ and/or ARB use & 70.2 & 67.1 & 72.5 & 0.280 \\
\hline$\beta$-blocker use & 32.9 & 22.6 & 40.5 & $<0.001$ \\
\hline Calcium channel blocker use & 57.5 & 47.3 & 65.0 & 0.001 \\
\hline Diuretics use & 46.0 & 32.9 & 55.5 & $<0.001$ \\
\hline
\end{tabular}

Abbreviations: eGFR, estimated glomerular filtration rate; CaXP product, Calcium-phosphorous product; LVEDV, left ventricular enddiastolic volume; LVESV, left ventricular end-systolic volume; LAD, left atrial diameter; LVMI, left ventricular mass index; LVH, left ventricular hypertrophy; LVM, left ventricular mass; LVEF, left ventricular ejection fraction; mwFS, midwall fraction shortening; EDT, E-wave deceleration time; E, peak early transmitral filling wave velocity; Ea, early diastolic velocity of lateral mitral annulus; ACEI, angiotensin converting enzyme inhibitor; ARB, angiotensin II receptor blocker. 
Table 2: Determinants of abnormal echocardiographic findings of DM patients using binary logistic regression analysis

\begin{tabular}{|c|c|c|}
\hline \multirow[t]{2}{*}{ Echocardiographic findings } & \multicolumn{2}{|c|}{ Multivariate (stepwise) } \\
\hline & OR $(95 \%$ CI $)$ & $p$ \\
\hline \multicolumn{3}{|l|}{ Observed/predicted LVM $>128 \%$} \\
\hline Body mass index (per $1 \mathrm{~kg} / \mathrm{m}^{2}$ ) & $1.183(1.071-1.307)$ & 0.001 \\
\hline eGFR (per $1 \mathrm{~mL} / \mathrm{min} / 1.73 \mathrm{~m}^{2}$ ) & $0.961(0.936-0.987)$ & 0.003 \\
\hline \multicolumn{3}{|l|}{ mwFS $<14 \%$} \\
\hline Smoking (ever versus never) & $2.238(1.083-4.629)$ & 0.030 \\
\hline Albumin (per $1 \mathrm{~g} / \mathrm{dL}$ ) & $0.399(0.185-0.860)$ & 0.019 \\
\hline \multicolumn{3}{|l|}{$\mathrm{E} / \mathrm{Ea}>12$} \\
\hline Systolic blood pressure (per $1 \mathrm{mmHg}$ ) & $1.017(1.001-1.033)$ & 0.037 \\
\hline Fasting glucose (per 1 mg/dL) & $1.006(1.002-1.011)$ & 0.009 \\
\hline Hemoglobin (per $1 \mathrm{~g} / \mathrm{dL})$ & $0.640(0.529-0.774)$ & $<0.001$ \\
\hline
\end{tabular}

Values expressed as odds ratio (OR) and 95\% confidence interval (CI). Abbreviations are the same as in Table 1. Covariates in the multivariate model included age, sex, a history of smoking, hypertension, coronary artery disease and cerebrovascular disease, systolic and diastolic blood pressure, body mass index, albumin, fasting glucose, triglyceride, total cholesterol, hemoglobin, eGFR, CaXP product, uric acid, proteinuria, and medications use including ACEI and/or ARB, $\beta$-blocker, calcium channel blocker and diuretics.

and systolic LV function directly through extracellular matrix protein cross-linkage and/or altered calcium handling [6]. Furthermore, AGEs may indirectly impair diastolic and systolic LV function through interactions with cardiac AGE receptors, thereby causing low-grade inflammation, increased oxidative stress and altered gene expressions $[6,7]$. Therefore, it is possible that AGEs have a negative impact on LV remodeling $[6,7]$. This impact may be especially relevant in patients with type $2 \mathrm{DM}$ due to chronic hyperglycemia and hyperlipidemia which can induce the formation of AGEs and also oxidative stress and low-grade inflammation, thereby leading to increased production of AGEs [6-8].

\section{LVH and inappropriate LVM}

The reported prevalence of LVH in patients with type 2 DM ranges from $19 \%$ to $56 \%$ in different studies [9-11]. In the present study, the prevalence of LVH was $59.1 \%$ in the patients with type $2 \mathrm{DM}$, which may have been due to the high prevalence of HTN $(87.5 \%)$ in our study cohort with CKD. In addition, the patients with DM also had a high prevalence of inappropriate LVM (69.5\%). Various alterations in hemodynamic and metabolic function have been reported to affect the structure and function of the heart in patients with CKD, and an excessive increase in LVM, a condition termed 'inappropriate LVM', has been reported in patients with CKD to compensate for these alterations $[12,13]$. Several studies have reported that predicted LVM according to the sex, height ${ }^{2.7}$, and hemodynamic load of a patient can be used to assess inappropriate LVM, and that the appropriateness of LVM can be estimated by the ratio of observed to predicted LVM [14, 15]. Recent studies have reported that inappropriate LVM and LVH occur in a significant proportion of patients with arterial HTN and aortic stenosis, and that this has a negative impact on the prognosis of CVD [16-20].

\section{LV systolic dysfunction}

Most previous studies have reported a high rate of LV systolic dysfunction in patients with DM, ranging from $5 \%$ to $21.8 \%$ [9, 10, 21]. LV systolic function can be estimated using conventional methods such as LVEF or by methods independent of geometry such as mwFS. Both of these systolic parameters have been reported to be good predictors of cardiovascular events in patients with renal failure [22]. In the present study, the rates of LVEF $<50 \%$ and mwFS $<14 \%$ were $7.2 \%$ and $22.6 \%$, respectively, which is consistent with previous studies.

\section{LV diastolic dysfunction}

LV diastolic dysfunction has been reported to occur in $25 \%$ to $75 \%$ of patients with diabetes $[9,10,23-25]$. We used the E/Ea ratio to define diastolic dysfunction according to tissue Doppler imaging. It has been reported that not performing tissue Doppler imaging can exclude up to $25 \%$ of patients with pseudonormalization which may then go unnoticed [10]. The E/Ea ratio has been reported to be significantly correlated with both LV diastolic function and filling pressure [26, 27]. In addition, an enlarged LA has been reported to be a marker of adverse cardiovascular outcomes including stroke, congestive HF, atrial fibrillation, and cardiovascular death in various 
Multivariate (stepwise)

Unstandardized coefficient $\beta(95 \% \mathrm{CI})$

$p$

Observed/predicted LVM
Smoking (ever versus never)
Body mass index (per $1 \mathrm{~kg} / \mathrm{m}^{2}$ )
Albumin (per $1 \mathrm{~g} / \mathrm{dL}$ )
eGFR (per $1 \mathrm{~mL} / \mathrm{min} / 1.73 \mathrm{~m}^{2}$ )
mwFS
Male versus female
Albumin (per $1 \mathrm{~g} / \mathrm{dL})$
Total cholesterol (per $1 \mathrm{mg} / \mathrm{dL})$
E/Ea
Systolic blood pressure (per $1 \mathrm{mmHg}$ )
Albumin (per $1 \mathrm{~g} / \mathrm{dL})$
Fasting glucose $($ per $1 \mathrm{mg} / \mathrm{dL})$
Hemoglobin $($ per $1 \mathrm{~g} / \mathrm{dL})$
$\beta$-blocker use
Diuretics use

Observed/predicted LVM

Smoking (ever versus never)

16.009 (0.761 31.257)

0.040

$2.089(0.202,3.977)$

0.030

$-19.605(-36.773,-2.438)$

0.025

$-0.586(-1.168,-0.004)$

0.049

$-1.493(-2.641,-0.345)$

0.011

$1.956(0.679,3.234)$

0.003

$-0.014(-0.025,-0.002)$

0.019

$$
\begin{gathered}
0.036(0.008,0.063) \\
-1.852(-3.331,-0.373) \\
0.009(0.000,0.017) \\
-0.728(-1.042,-0.413) \\
1.528(0.247,2.810) \\
1.417(0.102,2.732)
\end{gathered}
$$

0.012

0.014

0.046

$<0.001$

0.020

0.035

Values expressed as unstandardized coefficient $\beta$ and 95\% confidence interval (CI). Abbreviations are the same as in Table 1. Covariates in the multivariate model included age, sex, a history of smoking, hypertension, coronary artery disease and cerebrovascular disease, systolic and diastolic blood pressure, body mass index, albumin, fasting glucose, triglyceride, total cholesterol, hemoglobin, eGFR, CaXP product, uric acid, proteinuria, and medications use including ACEI and/or ARB, $\beta$-blocker, calcium channel blocker and diuretics.

pathologic conditions $[28,29]$. Both pressure and volume overload can contribute to enlargement of the left artery, and patients with a large left artery may have impaired LV diastolic function [28]. In the present study, the patients with CKD and DM had a larger LA diameter, higher E/ Ea ratio, and higher rate of $\mathrm{E} / \mathrm{Ea}>12$ compared to those without DM.

There are several limitations to this study. First, we excluded patients with mitral valve disease, atrial fibrillation, and inadequate image visualization. Hence, our results cannot be applied to these patients, and the generalizability of the results is limited. Second, we included patients with DM regardless of the duration of $\mathrm{DM}$, and a longer duration can result in more diverse effects on heart function. Therefore, we could not assess the effect of the duration DM on echocardiographic findings. Third, this study was cross-sectional, and subsequent clinical prognosis could not be confirmed. Future study of clinical outcomes needed to be addressed. In addition, we did not quantitatively assess proteinuria, so could not fully analyze the impact of proteinuria. Finally, antihypertensive drug treatment can influence the geometry and functional parameters of the left ventricle. However, due to ethical concerns, we did not withhold any drugs at the time of the echocardiography evaluations. However, in order to investigate the influence of drugs, we included various classes of antihypertensive drugs in the analysis. Our results showed that $\beta$-blockers and diuretics were associated with an increased E/Ea ratio, however this may have been due to selection bias.

In conclusion, in our study cohort of patients with stage 3-5 CKD, the prevalence of echocardiographic abnormalities including inappropriate LVM, and LV systolic and diastolic dysfunction was higher in the patients with DM. Traditional cardiovascular risk factors including male sex, smoking, HTN, obesity, hyperglycemia, and dyslipidemia, and nontraditional risk factors including malnutrition, anemia and decreased renal function were associated with abnormal echocardiographic findings in the patients with CKD and DM.

\section{MATERIALS AND METHODS}

\section{Study patients and design}

This study was conducted at the Outpatient Department of Internal Medicine at a regional hospital in southern Taiwan, and enrolled 356 patients with CKD stages 3 to 5 from January 2007 to May 2010. Patients with evidence of kidney damage for more than 3 months were classified into three groups according to the stage of CKD as assessed by eGFR as recommended in the 
National Kidney Foundation-Kidney Disease Outcomes Quality Initiative (K/DOQI) guidelines [30] as follows: stage 3,30 to $59 \mathrm{~mL} / \mathrm{min} / 1.73 \mathrm{~m}^{2}$; stage 4 , eGFR 15 to 29 $\mathrm{mL} / \mathrm{min} / 1.73 \mathrm{~m}^{2}$; and stage 5 , eGFR $<15 \mathrm{~mL} / \mathrm{min} / 1.73$ $\mathrm{m}^{2}$. We excluded patients with significant mitral valve disease and images of insufficient quality, and also those receiving dialysis. The study protocol was approved by the Institutional Review Board of Kaohsiung Medical University Hospital, and all participants provided written informed consent to participate in this study. The methods were carried out in accordance with the approved guidelines.

\section{Evaluation of cardiac structure and function}

All echocardiographic examinations were performed by two experienced cardiologists using a VIVID 7 system (General Electric Medical Systems, Horten, Norway), with the patient lying quietly in the left decubitus position. The cardiologists were blinded to the patients' clinical data. Two-dimensional and two-dimensionally guided M-mode images were recorded from standardized views. Echocardiographic parameters including LV end-diastolic volume, LVESV, LA diameter, LV internal diameter in diastole (LVIDd), LV posterior wall thickness in diastole (LVPWTd), interventricular septal wall thickness in diastole (IVSTd), E, Ea, and E/Ea ratio were recorded. LV systolic function was assessed according to LVEF and mwFS [31]. The LVM was calculated using a modification of Devereux's method: LVM $=1.04 \times[($ IVSTd + LVIDd + LVPWTd $)^{3}-$ LVIDd $^{3}$ ] - 13.6g [32]. LVMI was calculated as LVM/body surface area, and LVH was defined according to the 2007 European Society of Hypertension/ European Society of Cardiology guidelines [33]. Inappropriate LVM was assessed according to the ratio of observed to predicted LVM, where predicted LVM $=55.37$ $+6.64 \times$ height $\left(\mathrm{m}^{2.7}\right)+0.64 \times$ stroke work $-18.07 \times$ sex $($ male $=1$, female $=2)$ [14]. Stroke work was estimated as systolic $\mathrm{BP} \times$ volume, and converted to gram meters by multiplying by 0.0144 . 'Inappropriate' LVM was defined as an observed value more than $28 \%$ of the predicted value (i.e. observed/predicted LVM > 128\%) [14, 15]. Raw ultrasound data were recorded and analyzed offline by a cardiologist blinded to other data using EchoPAC software (GE Medical Systems). Echocardiographic data were recorded from three consecutive beats and then averaged.

\section{Collection of demographic, medical, and laboratory data}

Data including age, sex, smoking history (ever vs. never), and comorbidities were recorded from the patients' medical records or interviews. BMI was calculated as the weight in kilograms divided by the height in meters squared. Blood and urine samples were obtained from the patients within 1 month of enrollment into the study. and the laboratory data were obtained from fasting blood samples using an autoanalyzer (Roche Diagnostics $\mathrm{GmbH}$, D-68298 Mannheim COBAS Integra 400). Levels of serum creatinine were measured using the compensated Jaffé method (kinetic alkaline picrate) using a Roche/ Integra 400 Analyzer (Roche Diagnostics, Mannheim, Germany) with a calibrator that could be traced in isotopedilution mass spectrometry [34]. The eGFR was calculated using the equation reported in the Modification of Diet in Renal Disease (MDRD) study [35]. A positive result was defined as a score of $1+$ or more. Data regarding the use of medications including angiotensin converting enzyme inhibitors (ACEIs), angiotensin II receptor blockers (ARBs), $\beta$-blockers, calcium channel blockers, and diuretics during the study period were recorded from the patients' medical records.

\section{Statistical analysis}

All statistical analyses were performed using SPSS software for Windows version 19.0 (SPSS Inc. Chicago, USA). Data were expressed as percentages, means \pm standard deviations, and medians (25th-75th percentile) for triglycerides. Between-group differences were assessed using the chi-square test for categorical variables and the independent $t$-test for continuous variables. Multivariate binary logistic analysis and linear regression analysis were used to identify factors associated with abnormal echocardiographic findings in the patients with CKD and DM. Covariates included in the multivariate model included age, sex, smoking history, HTN, CAD, cerebrovascular disease, systolic and diastolic BP, eGFR, proteinuria and BMI, and levels of albumin, fasting glucose, triglycerides, total cholesterol, hemoglobin, CaXP product and uric acid, as well as the use of medications including ACEIs, ARBs, $\beta$-blockers, calcium channel blockers and diuretics. A $p$ value of less than 0.05 was considered to indicate statistical significance.

\section{Abbreviations}

Diabetes mellitus (DM) chronic kidney disease (CKD) heart failure (HF) cardiovascular disease (CVD) left ventricular (LV) LV hypertrophy (LVH) coronary artery disease (CAD) hypertension (HTN) blood pressure (BP) body mass index (BMI) LV end-systolic volume (LVESV) left atrial (LA) LV mass (LVM) peak early transmitral filling wave velocity (E) early diastolic mitral velocity (Ea) midwall fractional shortening (mwFS) LV ejection fraction (LVEF) estimated glomerular filtration rate (eGFR) calcium-phosphorous (CaXP) glycation endproducts (AGEs) LV internal diameter in diastole (LVIDd) LV posterior wall thickness in diastole (LVPWTd) interventricular septal wall thickness in 
diastole (IVSTd) angiotensin converting enzyme inhibitors (ACEIs) angiotensin II receptor blockers (ARBs).

\section{Author contributions}

Conceived and designed the experiments: P.Y.W., J.C.H., S.C.C. and L.I.C. Performed the experiments: P.Y.W., J.C.H., S.C.C. and L.I.C. Analyzed the data: P.Y.W., J.C.H., S.C.C. and L.I.C. Prepare Tables and Figure: P.Y.W. and L.I.C. Wrote the paper: P.Y.W. and L.I.C. All authors reviewed the manuscript.

\section{CONFLICTS OF INTEREST}

We have no financial interest in the information contained in the manuscript.

\section{REFERENCES}

1. American Diabetes Association. Standards of medical care in diabetes--2013. Diabetes care. 2013; 36:S11-66.

2. Kannel WB, McGee DL. Diabetes and cardiovascular disease. The Framingham study. JAMA. 1979; 241:2035-8.

3. Paoletti E, Bellino D, Cassottana P, Rolla D, Cannella G. Left ventricular hypertrophy in nondiabetic predialysis CKD. Am J Kidney Dis. 2005; 46:320-7.

4. Stewart GA, Gansevoort RT, Mark PB, Rooney E, McDonagh TA, Dargie HJ, Stuart R, Rodger C, Jardine AG. Electrocardiographic abnormalities and uremic cardiomyopathy. Kidney Int. 2005; 67:217-26.

5. Somaratne JB, Whalley GA, Bagg W, Doughty RN. Early detection and significance of structural cardiovascular abnormalities in patients with Type 2 diabetes mellitus. Expert Rev Cardiovasc Ther. 2008; 6:109-25.

6. Hartog JW, Voors AA, Bakker SJ, Smit AJ, van Veldhuisen DJ. Advanced glycation end-products (AGEs) and heart failure: pathophysiology and clinical implications. Eur J Heart Fail. 2007; 9:1146-55.

7. Borbely A, Papp Z, Edes I, Paulus WJ. Molecular determinants of heart failure with normal left ventricular ejection fraction. Pharmacy Rep. 2009; 61:139-45.

8. Daffu G, del Pozo CH, O'Shea KM, Ananthakrishnan R, Ramasamy R, Schmidt AM. Radical roles for RAGE in the pathogenesis of oxidative stress in cardiovascular diseases and beyond. Int J Mol Sci. 2013; 14:19891-910.

9. Muddu M, Mutebi E, Mondo C. Prevalence, types and factors associated with echocardiographic abnormalities among newly diagnosed diabetic patients at Mulago Hospital. Afr Health Sci. 2016; 16:183-93.

10. Srivastava PM, Calafiore P, Macisaac RJ, Patel SK, Thomas MC, Jerums G, Burrell LM. Prevalence and predictors of cardiac hypertrophy and dysfunction in patients with Type 2 diabetes. Clin Sci (Lond). 2008; 114:313-20.
11. Somaratne JB, Whalley GA, Poppe KK, ter Bals MM, Wadams G, Pearl A, Bagg W, Doughty RN. Screening for left ventricular hypertrophy in patients with type 2 diabetes mellitus in the community. Cardiovasc Diabetol. 2011; 10:29.

12. Veves A, Akbari CM, Primavera J, Donaghue VM, Zacharoulis D, Chrzan JS, DeGirolami U, LoGerfo FW, Freeman R. Endothelial dysfunction and the expression of endothelial nitric oxide synthetase in diabetic neuropathy, vascular disease, and foot ulceration. Diabetes. 1998; 47:457-63.

13. Palmieri V, de Simone G, Roman MJ, Schwartz JE, Pickering TG, Devereux RB. Ambulatory blood pressure and metabolic abnormalities in hypertensive subjects with inappropriately high left ventricular mass. Hypertension. 1999; 34:1032-40.

14. de Simone G, Devereux RB, Kimball TR, Mureddu GF, Roman MJ, Contaldo F, Daniels SR. Interaction between body size and cardiac workload: influence on left ventricular mass during body growth and adulthood. Hypertension. 1998; 31:1077-82.

15. Nardi E, Palermo A, Mule G, Cusimano P, Cottone S, Cerasola G. Left ventricular hypertrophy and geometry in hypertensive patients with chronic kidney disease. J Hypertens. 2009; 27:633-41.

16. Chinali M, De Marco M, D'Addeo G, Benincasa M, Romano C, Galderisi M, de Simone G. Excessive increase in left ventricular mass identifies hypertensive subjects with clustered geometric and functional abnormalities. J Hypertens. 2007; 25:1073-8.

17. de Simone G, Palmieri V, Koren MJ, Mensah GA, Roman MJ, Devereux RB. Prognostic implications of the compensatory nature of left ventricular mass in arterial hypertension. J Hypertens. 2001; 19:119-25.

18. de Simone G, Verdecchia P, Pede S, Gorini M, Maggioni AP. Prognosis of inappropriate left ventricular mass in hypertension: the MAVI Study. Hypertension. 2002; 40:470-6.

19. Lavie CJ, Patel DA, Milani RV, Ventura HO, Shah S, Gilliland Y. Impact of echocardiographic left ventricular geometry on clinical prognosis. Prog Cardiovasc Dis. 2014; 57:3-9.

20. Oktay AA, Lavie CJ, Milani RV, Ventura HO, Gilliland YE, Shah S, Cash ME. Current Perspectives on Left Ventricular Geometry in Systemic Hypertension. Prog Cardiovasc Dis. 2016; 59:235-46.

21. Chareonthaitawee P, Sorajja P, Rajagopalan N, Miller TD, Hodge DO, Frye RL, Gibbons RJ. Prevalence and prognosis of left ventricular systolic dysfunction in asymptomatic diabetic patients without known coronary artery disease referred for stress single-photon emission computed tomography and assessment of left ventricular function. Am Heart J. 2007; 154:567-74.

22. Kazda M, Salzer J, Reiter I. Photosynthetic capacity in relation to nitrogen in the canopy of a Quercus robur, 
Fraxinus angustifolia and Tilia cordata flood plain forest. Tree physiol. 2000; 20:1029-37.

23. Wai B, Patel SK, Ord M, MacIsaac RJ, Jerums G, Srivastava PM, Burrell LM. Prevalence, predictors and evolution of echocardiographically defined cardiac abnormalities in adults with type 1 diabetes: an observational cohort study. $\mathrm{J}$ Diabetes Complications. 2014; 28:22-8.

24. Dodiyi-Manuel ST, Akpa MR, Odia OJ. Left ventricular dysfunction in normotensive type II diabetic patients in Port Harcourt, Nigeria. Vasc Health Risk Manag. 2013; 9:529-33.

25. Faden G, Faganello G, De Feo S, Berlinghieri N, Tarantini L, Di Lenarda A, Faggiano P, Cioffi G. The increasing detection of asymptomatic left ventricular dysfunction in patients with type 2 diabetes mellitus without overt cardiac disease: data from the SHORTWAVE study. Diabetes Res Clin Pract. 2013; 101:309-1.

26. Khouri SJ, Maly GT, Suh DD, Walsh TE. A practical approach to the echocardiographic evaluation of diastolic function. J Am Soc Echocardiogr. 2004; 17:290-7.

27. Nagueh SF, Middleton KJ, Kopelen HA, Zoghbi WA, Quinones MA. Doppler tissue imaging: a noninvasive technique for evaluation of left ventricular relaxation and estimation of filling pressures. J Am Coll Cardiol. 1997; 30:1527-33.

28. Abhayaratna WP, Seward JB, Appleton CP, Douglas PS, Oh JK, Tajik AJ, Tsang TS. Left atrial size: physiologic determinants and clinical applications. J Am Coll Cardiol. 2006; 47:2357-63.

29. Kizer JR, Bella JN, Palmieri V, Liu JE, Best LG, Lee ET, Roman MJ, Devereux RB. Left atrial diameter as an independent predictor of first clinical cardiovascular events in middle-aged and elderly adults: the Strong Heart Study (SHS). Am Heart J. 2006; 151:412-8.

30. National Kidney Foundation. K/DOQI clinical practice guidelines for chronic kidney disease: evaluation, classification, and stratification. Am J Kidney Dis. 2002; 39:S1-266.

31. Shimizu G, Conrad CH, Gaasch WH. Phase-plane analysis of left ventricular chamber filling and midwall fiber lengthening in patients with left ventricular hypertrophy. Circulation. 1987; 75:I34-9.

32. Devereux RB, Alonso DR, Lutas EM, Gottlieb GJ, Campo E, Sachs I, Reichek N. Echocardiographic assessment of left ventricular hypertrophy: comparison to necropsy findings. Am J Cardiol. 1986; 57:450-8.

33. Mancia G, De Backer G, Dominiczak A, Cifkova R, Fagard R, Germano G, Grassi G, Heagerty AM, Kjeldsen SE, Laurent S, Narkiewicz K, Ruilope L, Rynkiewicz A, et al. 2007 Guidelines for the Management of Arterial Hypertension: The Task Force for the Management of Arterial Hypertension of the European Society of Hypertension (ESH) and of the European Society of Cardiology (ESC). J Hypertens. 2007; 25:1105-87.

34. Vickery S, Stevens PE, Dalton RN, van Lente F, Lamb EJ. Does the ID-MS traceable MDRD equation work and is it suitable for use with compensated Jaffe and enzymatic creatinine assays? Nephrol Dial Transplant. 2006; 21:2439-45.

35. Levey AS, Bosch JP, Lewis JB, Greene T, Rogers N, Roth D. A more accurate method to estimate glomerular filtration rate from serum creatinine: a new prediction equation. Modification of Diet in Renal Disease Study Group. Ann Intern Med. 1999; 130:461-70. 